\title{
Report on the 33rd Asia-Pacific Academy of Ophthalmology Congress, Hong Kong, 8-11 February 2018
}

Carmen KM Chan ${ }^{1,2}$, MB BChir (Cantab), MRCP(UK), FCOphth(HK), FHKAM (Ophth), FRCSEd(Ophth); Clement CY Tham ${ }^{1,2,3}$, BM BCh (Oxon), FCOphth (HK), FHKAM (Ophth), FRCOphth, FRCS (Glas), FCSHK

${ }^{1}$ Department of Ophthalmology \& Visual Sciences, The Chinese University of Hong Kong, Hong Kong

${ }^{2}$ Hong Kong Eye Hospital, Kowloon, Hong Kong

${ }^{3}$ Department of Ophthalmology \& Visual Sciences, Prince of Wales Hospital, Shatin, New Territories, Hong Kong

Correspondence and reprint requests:

Prof Clement CY Tham, Hong Kong Eye Hospital, 147K Argyle Street, Kowloon, Hong Kong.

Email:clemtham@cuhk.edu.hk

\section{Introduction}

The 33rd Asia-Pacific Academy of Ophthalmology (APAO) 2018 Congress in conjunction with the 29th Hong Kong Ophthalmological Symposium took place at the Hong Kong Convention and Exhibition Centre from 8 to 11 February 2018. It was attended by 5206 delegates from 63 countries.

\section{Scientific Program}

Under the chairmanship of Prof Dennis Lam, the scientific program committee (http://2018.apaophth.org/programcommittee/), with its 117 members from across the world, put together the invited scientific program. The invited scientific program comprised 177 sessions, covered 17 subspecialty areas, and was presented by 602 distinguished clinicians and scientists from around the world. In addition to the established clinical ophthalmology subspecialties, the program also encompassed areas such as ophthalmic education, translational research and visual sciences, which are important for the future development of ophthalmology (Figure 1).

In the submitted program, out of 1500 submissions, 274 abstracts were presented in Free Paper sessions, while 381 abstracts were presented as scientific posters. A total of 22 submitted instruction courses were also presented. Additionally, there were a total of 389 e-poster and 62 video abstract presentations. The presented abstracts covered 16 different subspecialties and represented 28 different countries across the globe. For the first time in an APAO Congress, awards were presented to the best submitted free papers $(26$ oral presentation awards chosen by the Abstract Review Committee), as well as the most popular posters, e-posters, and videos (5 in each category, selected based on delegate voting).

In addition, the APAO 2018 Congress was the first APAO Congress to feature 'wet lab' surgical teaching sessions (Figure 2). With 21 sponsored courses covering a wide range of topics, including intravitreal injection, SMILE, phacoemulsification, DMEK, DSAEK and more, the popular sessions provided delegates with interactive hands-on experience and were fully booked even before the Congress began.

\section{Social Program}

The Opening Ceremony was held on 8 February 2018 with Prof Sophia Chan, Hong Kong Secretary for Food and Health, as the Guest of Honor. After opening speeches from Prof Chan and other distinguished guests, the APAO named awards and lectures were presented (Figure 3).

The APAO 2018 Presidential Dinner was held on racing night at the Hong Kong Jockey Club on February 7, 2018, where members of the scientific program committee and other guests enjoyed horse racing and tried their luck at the betting counters. 


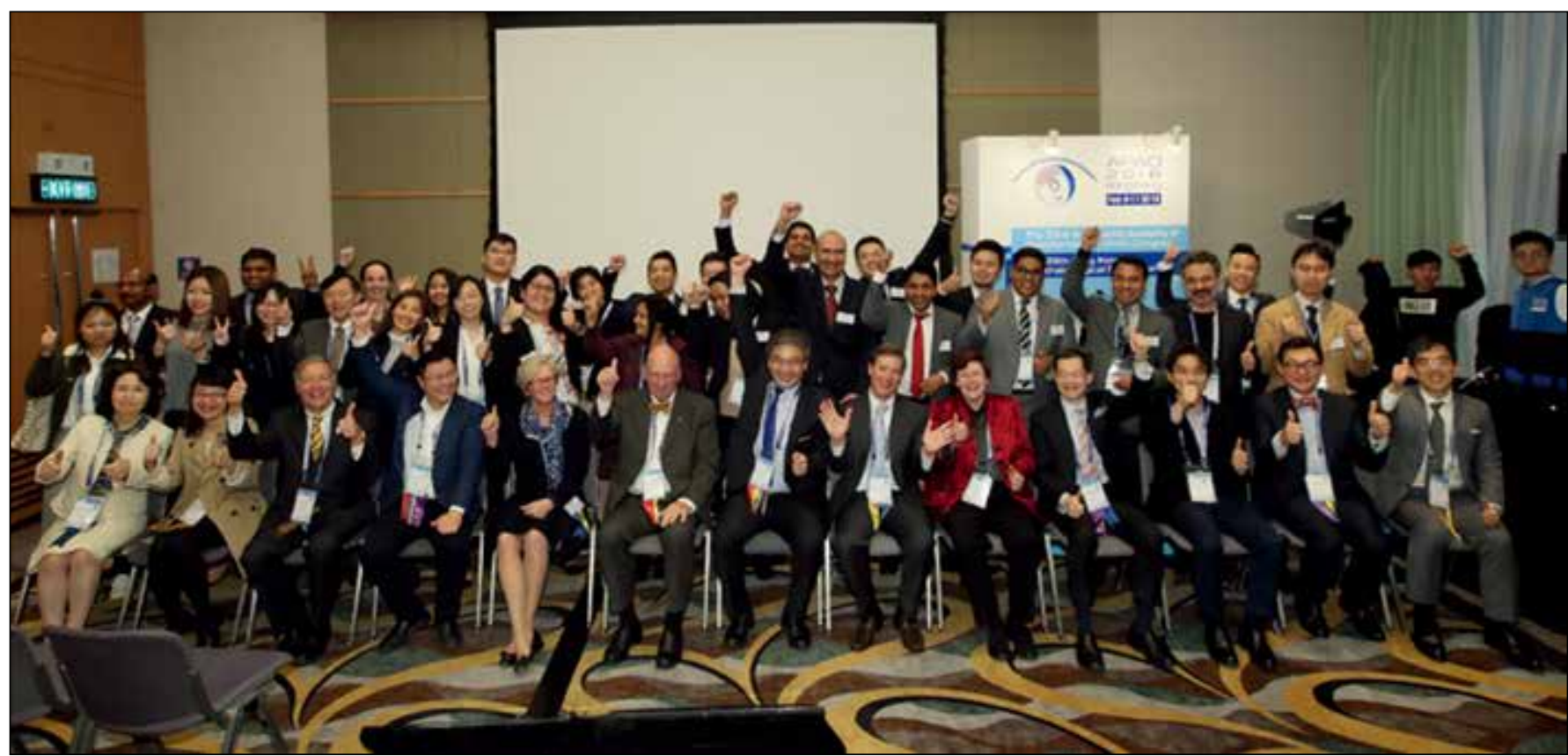

Figure 1. Academy of Asia-Pacific Professors of Ophthalmology Academic Development Mentorship Scheme \& Asia-Pacific Vitreoretina Society Leadership Development Program: Meeting the Masters and Keynote Lecture, 9 February 2018.

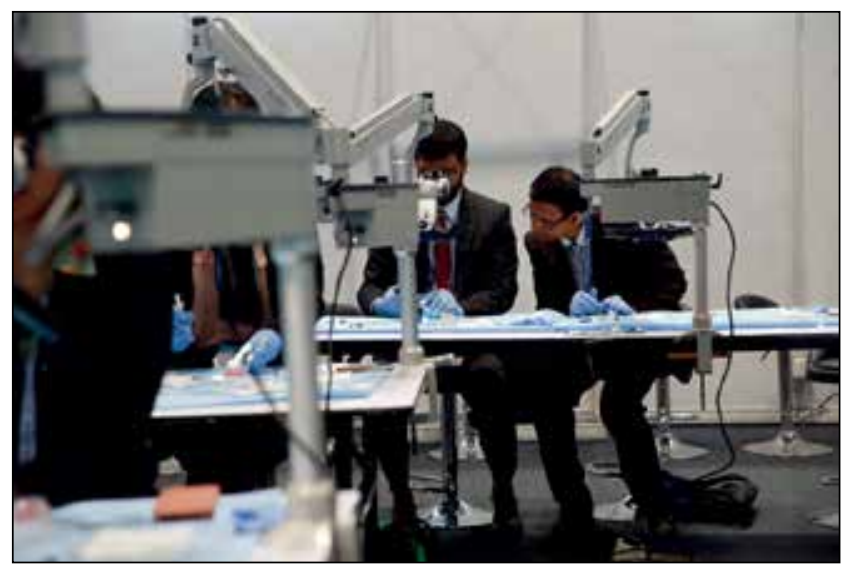

Figure 2. Participants at one of the many Wet Laboratory Instruction Courses.

The 3rd APAO Charity Run took place on the morning of 10 February 2018, starting from the Hong Kong Observation Wheel. More than 180 participants raised nearly US\$13000, which was divided equally between the new APAO Satellite Congress educational program and Blind Sports Hong Kong. A complete list of winners in the different race categories is available online (http://2018.apaophth.org/charity-runresult/). On the same evening, the APAO 2018 Gala Dinner, held at the Hong Kong Convention and Exhibition Centre, offered delegates a taste of old Hong Kong, including traditional Chinese medicine, fresh gai daan zai and more. The APAO awards (Distinguished Service, Prevention of Blindness, Senior Achievement, Achievement), best scientific

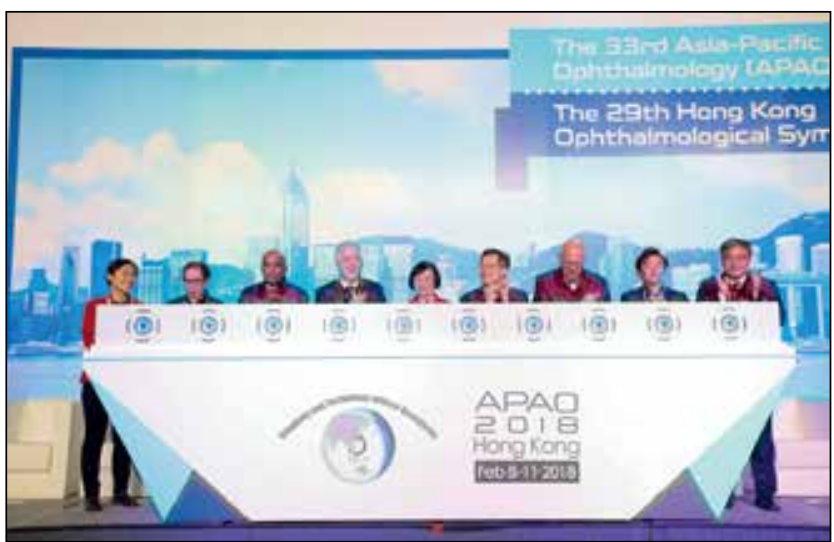

Figure 3. Opening Ceremony, 8 February 2018. From left: Dr Carmen Chan, Prof Jimmy Lai, Dr Gullapalli Nag Rao, Prof Charles McGhee, Prof Sophia Chan (Guest of Honour), Prof Clement Tham, Dr Hugh Taylor, Dr Jeffrey Pong, and Prof Dennis Lam.

paper awards and Yasuo Tano Travel grants were presented during the Gala Dinner. The full list of award recipients can be found in the APAO 2018 program book (http://2018. apaophth.org/publications/)

The APAO 2018 social program also included the first APAO Women in Ophthalmology lunch, Young Ophthalmologists' night and the Leadership Development Program Alumni Reception.

\section{Conclusion}

APAO 2018 no doubt achieved the objectives of providing an 
excellent platform for professional and scientific exchanges in the field of ophthalmology, as well as raising the standard of eye care through world-class educational programs. We look forward to the future APAO Congresses. The full details of the APAO 2018 Congress, including a PDF copy of the complete program book can be found on http://2018. apaophth.org/.

\section{Author contributions}

Concept or design: CCYT

Acquisition of data: All

Analysis or interpretation of data: All

Drafting of the article: All

Critical revision for important intellectual content: All

All authors had full access to the data, contributed to the study, approved the final version for publication, and take responsibility for its accuracy and integrity.

\section{Conflicts of Interest}

Clement Tham was the Congress President of the AsiaPacific Academy of Ophthalmology (APAO) Congress 2018 Hong Kong, and the Secretary-General \& CEO of APAO. Carmen Chan was the Chair of the APAO 2018 Organizing Committee.

\section{Acknowledgment}

The authors would like to thank Miss Cynthia Wong and Miss Sydney Stonner of the APAO Secretariat for providing statistics and documents of the Congress as references for this report. All photos copyright APAO. Used with permission from APAO. Other photos are available at APAO 2018 online album. http://2018.apaophth.org/online-album/

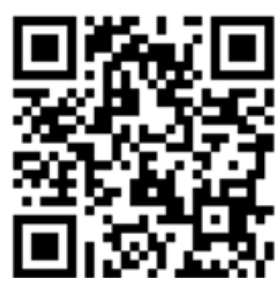

